\title{
Recombination analysis based on the complete genome of bocavirus
}

\author{
Xingli Fu ${ }^{1,2+}$, Xiaochun Wang ${ }^{1 \dagger}$, Bin $\mathrm{Ni}^{1}$, Hongxing Shen ${ }^{1}$, Hua Wang ${ }^{1}$, Xiaodan Zhang ${ }^{1}$, Shengxia Chen ${ }^{1}$, \\ Shihe Shao ${ }^{1}$ and Wen Zhang ${ }^{1 *}$
}

\begin{abstract}
Bocavirus include bovine parvovirus, minute virus of canine, porcine bocavirus, gorilla bocavirus, and Human bocaviruses 1-4 (HBoVs). Although recent reports showed that recombination happened in bocavirus, no systematical study investigated the recombination of bocavirus. The present study performed the phylogenetic and recombination analysis of bocavirus over the complete genomes available in GenBank. Results confirmed that recombination existed among bocavirus, including the likely inter-genotype recombination between HBoV1 and HBoV4, and intra-genotype recombination among HBoV2 variants. Moreover, it is the first report revealing the recombination that occurred between minute viruses of canine.
\end{abstract}

\section{Introduction}

Members of the genus Bocavirus are non-enveloped single-stranded DNA (ss-DNA) virus, which belong to the Parvoviridae family. The bocavirus genome is not segmented and contains a single molecule of linear, positive- or negative-sense DNA of 4,000-6,000 nucleotides in length [1]. Known members of bocavirus include bovine parvovirus (BPV), minute virus of canine (MVC), porcine bocavirus $(\mathrm{PBoV})$, gorilla bocavirus $(\mathrm{GBoV})$, and Human bocaviruses 1-4 (HBoV1-4).

The MVC genome shares about $43 \%$ identity with BPV over the genome level $[2,3]$. BPV was first identified in 1961 in samples from calves with diarrhea [4], while MVC was first isolated from canine fecal samples in 1970 [5]. HBoV was first described in pooled nasopharyngeal aspirates from children with respiratory infections in 2005, and was provisionally categorized into the genus bocavirus [1]. Subsequently, HBoV2, $\mathrm{HBoV} 3$, and $\mathrm{HBoV} 4$ were discovered, sharing a mean similarity of $80 \%$ with HBoV1, and all have been categorized into the genus bocavirus [6,7]. Recently, new bocavirus species were isolated from gorilla and swine, and most closely related to $\mathrm{HBoV}[8,9]$.

\footnotetext{
* Correspondence: z0216wen@hotmail.com

+ Contributed equally

'School of Medical Technology, Jiangsu University, 301 Xuefu Road,

Zhenjiang, Jiangsu 212013, PR China

Full list of author information is available at the end of the article
}

Although recently reports showed that recombination happened in bocavirus [8], no study has systematically investigated the recombination among bocavirus strains. In the present study, therefore, we analyzed the available complete bocavirus genome sequences in GenBank to elucidate the recombination among bocavirus strains.

\section{Methods \\ Sequences}

The study sequences comprised all the 121 available complete genome sequences of bocavirus from GenBank dated September 2010. Sequences were firstly screened to exclude patented and artificial mutants, and then aligned in the ClustalW program [10]. The alignment was manually adjusted for the correct reading frame. Sequences showing less than $1 \%$ divergence from each other were considered as the same. The remaining 54 $\mathrm{BoV}$ genomes included one $\mathrm{GBoV}$, one BPV, two PBoVs, three MVCs, and $47 \mathrm{HBoVs}$.

\section{Phylogenetic analysis}

Before phylogenetic analysis, multiple-alignment was performed in the ClustalW program. Phylogenetic trees were constructed using the neighbor-joining method and evaluated using the interior branch test method with Mega 4 software [11]. Percent bootstrap support was indicated at each node. GenBank accession no. was indicated at each branch.

\section{Ciomed Central}




\section{Recombination Detection}

The remaining 54 bocavirus genomes were re-aligned in the ClustalW program. Detection of potential recombinant sequences, identification of potential parental sequences, and localization of possible recombination break points were determined using the Recombination Detection Program (RDP)[12], GENECONV [13], BOOTSCAN [14], MaxChi [15], CHIMAERA [16], and SISCAN [17] methods embedded in RDP3 [18]. A Multiple-comparison-corrected P-value cutoff of 0.05 was used throughout.

\section{Results and Discussion}

Based on the 54 complete genomes, a phylogenetic tree was constructed (Figure 1). The genotypes of these bocavirus showed in the phylogenetic tree were consistent with the genotype information from the original sources. From the phylogenetic tree, we can see that $\mathrm{HBoV} 2$ and HBoV4 closely related and formed into one cluster; HBoV1 and HBoV3 clustered separately, and GBoV showed more related to HBoV1 than to the other HBoVs. Six potentially significant recombination events were found with a high degree of confidence ( $p$ value $\leq$ $4.4 \times 10^{-3}$ ) judged by the above-mentioned six recombination detection methods.

Figure 2 indicated the inter-genotype recombination events that occurred between HBoV1 and HBoV4, which lead to the recombinant cluster HBoV2. The BOOTSCAN plot of this recombination event was showed in Figure 2A, which used the lineages represented by NC_012729 and EU984244 as the parental strains, leading to the daughter lineage represented by GU048665. To confirm this recombination event, the relevant strains were analyzed by neighbor joining trees using MEGA4. Figure $2 \mathrm{~B}$ and $2 \mathrm{C}$ were two trees constructed on the non-recombinant region (position: 1-166 + 2967-end) and the recombinant region (position:1672966), respectively. In Figure 2B, all HBoV2 strains clustered closely with $\mathrm{HBoV} 3$ and $\mathrm{HBoV} 4$, while Figure $2 \mathrm{C}$ showed discordant phylogenetic relationships compared with Figure 2B, where HBoV2 strains clustered with HBoV1. The phylogenetic analysis confirmed the recombination event that occurred between HBoV1 and $\mathrm{HBoV} 4$, leading to the recombinant HBoV2.

Figure 3A-E indicated the other 5 recombinants identified in the present study. The BOOTSCAN plot of each recombination event was showed on the left side, while phylogenetic tree based on recombination regions and non-recombination regions of parental strains in each recombination event were indicated on the right side. Figure $3 \mathrm{~A}$ showed the recombinant occurred between two MVC strains, FJ899734[19] and AB158475 [20], leading to the recombinant NC_004442[3]. These recombination events provide the first evidence that

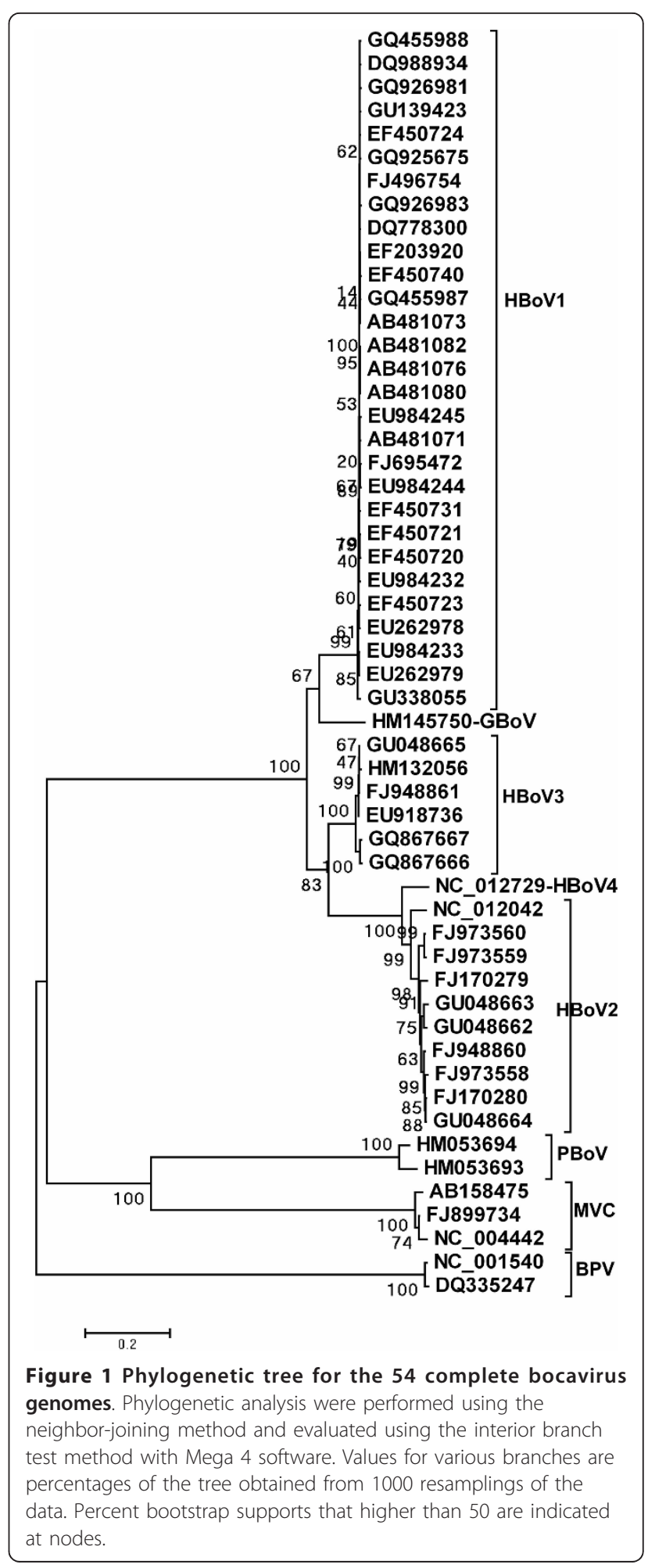

recombination could happened among MVC strains. Figure 3B showed a recombination event happened intra-genotypely between two HBoV2 strains, FJ948860 and GU048662, leading to the recombinant FJ973558, another HBoV2 strain. FJ948860 and GU048662 were 
A GU048665 $\square$ scanned against NC_012729
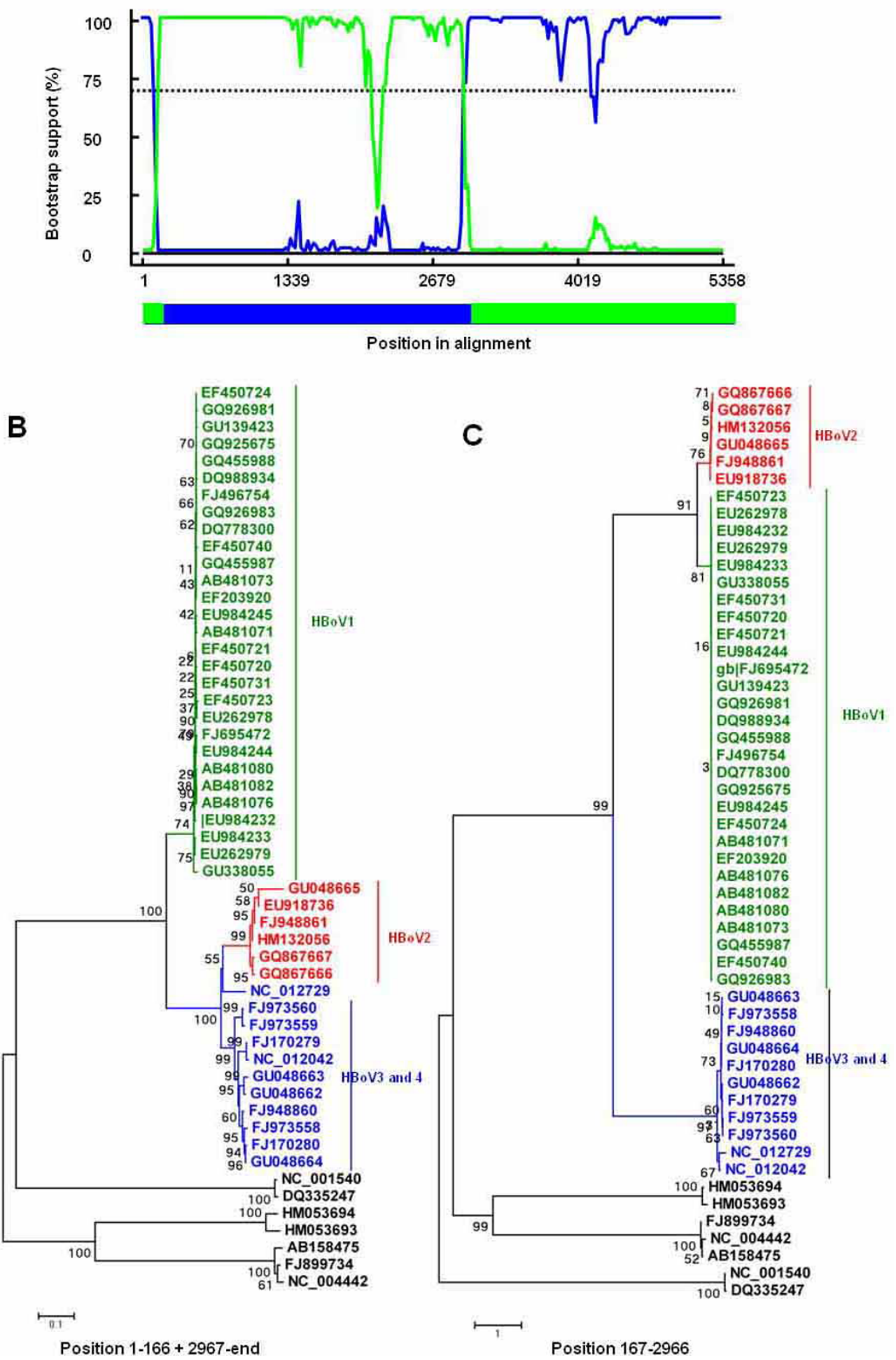

Figure 2 Identification of recombination between HBoV1 and HBoV4, which led to the recombinant cluster of HBoV2. (A) BOOTSCAN evidence for the recombination origin on the basis of pairwise distance, modeled with a window size 200, step size 20, and 100 Bootstrap replicates; (B) Neighbor joining tree (2,000 replicates, Kimura 2-parameter distance) constructed using the non-recombinant region (Position 1$166+2967-e n d) ;(C)$ Neighbor joining tree (2,000 replicates, Kimura 2-parameter distance) constructed using the recombinant region (Position 167-2966). 

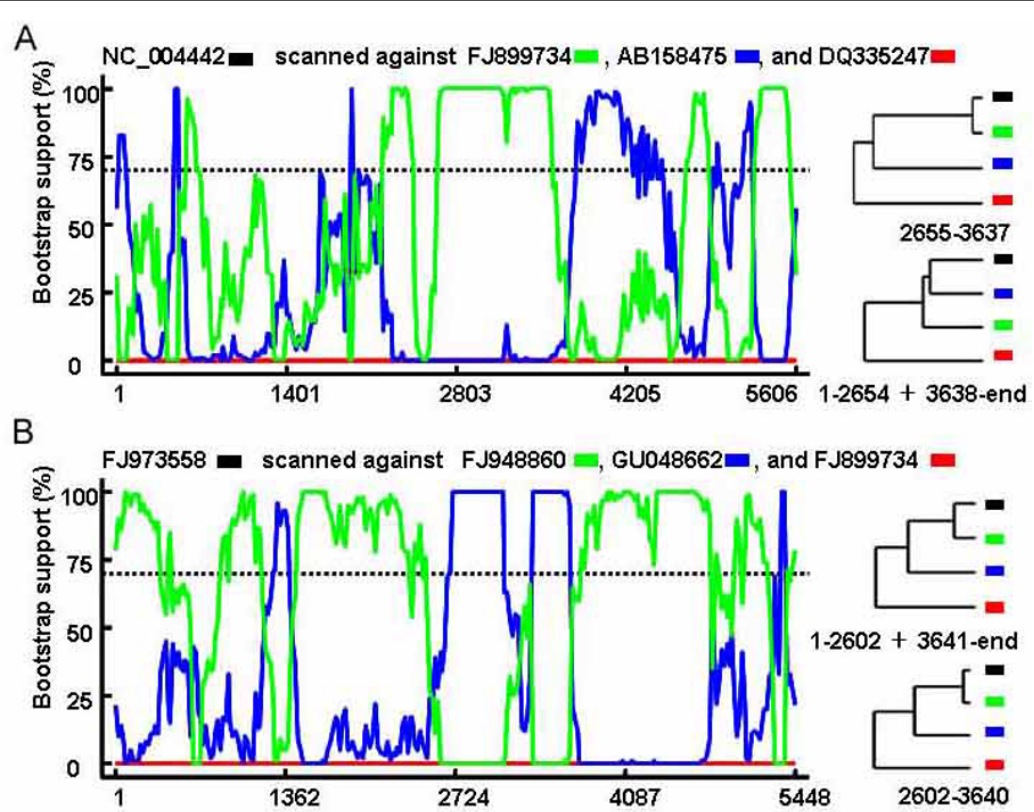

C GU048663 a scanned against GU048662 $=$, FJ170280 $=$, and FJ899734
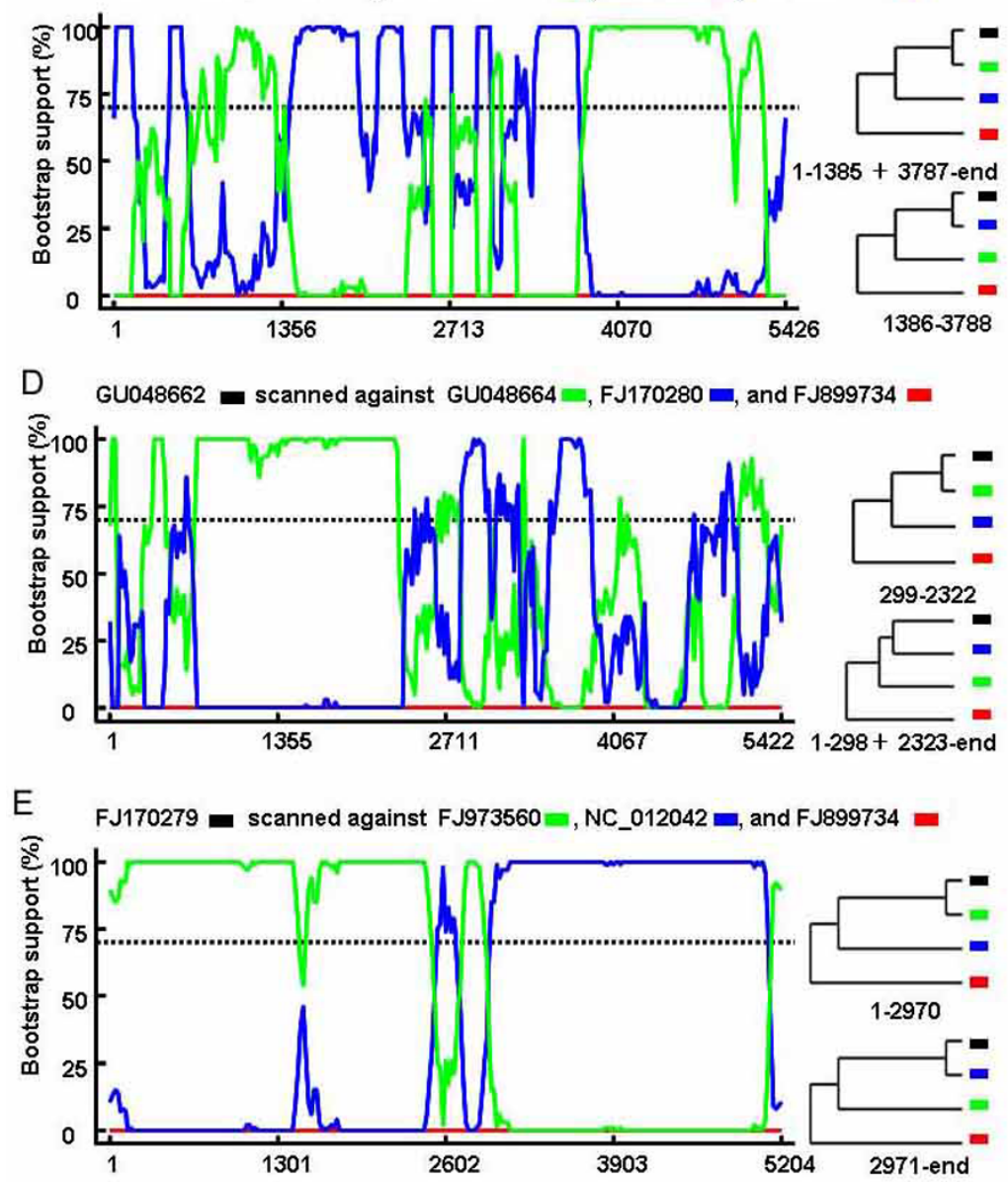

Figure 3 Identification of the other 5 recombination events. The left part of each panel was BOOTSCAN evidence for the recombination origin on the basis of pairwise distance, modeled with a window size 200, step size 20, and 100 Bootstrap replicates; The right part of each panel were phylogenetic trees constructed based on recombination regions and non-recombination regions using Mega 4 software. 
isolated from Australia in 2001 [7] and Thailand in 2007 according to the isolate information in GenBank, respectively, while FJ973558 was isolated from Tunisia in 2006 [8]. Figure 3C and 3D revealed two Bangpoo recombinants, GU048662 and GU048663, respectively. However, according to the isolate information in GenBank, GU048662, GU048663, and one of their parental isolates were isolated in the same lab in Thailand, therefore, it should be cared whether these recombination events non-naturally occurred by sequencing error and/or contamination in the lab. Figure $3 \mathrm{E}$ revealed recombination between the lineage represented by Nigeria HBoV2 isolate FJ973560 and Pakistan HBoV2 isolate lineage NC 012042, which led to a recombinant Pakistan isolate FJ170279. However, these three isolates were determined in the same lab $[6,8]$, therefore, whether this recombination event non-naturally occurred by sequencing error and/or contamination should be confirmed by further study.

For RNA viruses, recombination has been shown to be an important feature of their evolution [21-23], and single-stranded DNA parvoviruses have been shown to have a mutation rate approaching that of RNA viruses [24]. The HBoV sequences were previously considered to show very low protein and nucleotide sequence diversity [25]. Recently, however, other 3 different genotypes (HBoV2-4) were discovered, which reveals that the HBoVs own the property of high sequence diversity. The present study provide the evidence that recombination was observed through complete bocavirus genome analyses, including the likely inter-genotype recombination between $\mathrm{HBoV} 1$ and $\mathrm{HBoV} 4$, and intra-genotype recombination between $\mathrm{HBoV} 2$ variants. As a matter of fact, a recent study indicated HBoVs coinfection was detected [8], which will increase the chance of recombination between baocavirus strains.

\section{Conclusion}

Taken together, this study confirmed that recombination existed among bocavirus, including the likely inter-genotype recombination between $\mathrm{HBoV} 1$ and $\mathrm{HBoV} 4$, and intra-genotype recombination among $\mathrm{HBoV} 2$ variants. It is the first report revealing the recombination that occurred between minute virus strains of canine.

\section{Acknowledgements}

This work was supported by the Professional Research Foundation for Advanced Talents of Jiangsu University under Grant No.10JDG044 and No.10JDG059.

\section{Author details}

${ }^{1}$ School of Medical Technology, Jiangsu University, 301 Xuefu Road,

Zhenjiang, Jiangsu 212013, PR China. ${ }^{2}$ School of Medicine, Jiangsu University, 301 Xuefu Road, Zhenjiang, Jiangsu 212013, PR China.

\section{Authors' contributions}

WZ and XF conceived the study. WZ and XF wrote the paper. All authors performed recombination analysis and critically reviewed and approved the final manuscript.

\section{Competing interests}

The authors declare that they have no competing interests.

Received: 15 November 2010 Accepted: 20 April 2011 Published: 20 April 2011

\section{References}

1. Allander T, Tammi MT, Eriksson M, Bjerkner A, Tiveljung-Lindell A, Andersson B: Cloning of a human parvovirus by molecular screening of respiratory tract samples. Proc Natl Acad Sci USA 2005, 102:12891-12896.

2. Sun Y, Chen AY, Cheng F, Guan W, Johnson FB, Qiu J: Molecular characterization of infectious clones of the minute virus of canines reveals unique features of bocaviruses. J Virol 2009, 83:3956-3967.

3. Schwartz D, Green B, Carmichael LE, Parrish CR: The canine minute virus (minute virus of canines) is a distinct parvovirus that is most similar to bovine parvovirus. Virology 2002, 302:219-223.

4. Abinanti FR, Warfield MS: Recovery of a hemadsorbing virus (HADEN) from the gastrointestinal tract of calves. Virology 1961, 14:288-289.

5. Binn LN, Lazar EC, Eddy GA, Kajima M: Recovery and Characterization of a Minute Virus of Canines. Infect Immun 1970, 1:503-508.

6. Kapoor A, Slikas E, Simmonds P, Chieochansin T, Naeem A, Shaukat S, Alam MM, Sharif S, Angez M, Zaidi S, Delwart E: A newly identified bocavirus species in human stool. J Infect Dis 2009, 199:196-200.

7. Arthur $\mathrm{L}$, Higgins GD, Davidson GP, Givney RC, Ratcliff RM: A novel bocavirus associated with acute gastroenteritis in Australian children. PLoS Pathog 2009, 5:e1000391.

8. Kapoor A, Simmonds P, Slikas E, Li L, Bodhidatta L, Sethabutr O, Triki H, Bahri O, Oderinde BS, Baba MM, Bukbuk DN, Besser J, Bartkus J, Delwart E: Human bocaviruses are highly diverse, dispersed, recombination prone, and prevalent in enteric infections. J Infect Dis 2010, 201:1633-1643.

9. Cheng WX, Li JS, Huang CP, Yao DP, Liu N, Cui SX, Jin Y, Duan ZJ: Identification and nearly full-length genome characterization of novel porcine bocaviruses. PLoS One 2010, 5:e13583

10. Thompson JD, Higgins DG, Gibson TJ: CLUSTAL W: improving the sensitivity of progressive multiple sequence alignment through sequence weighting, position-specific gap penalties and weight matrix choice. Nucleic Acids Res 1994, 22:4673-4680.

11. Tamura K, Dudley J, Nei M, Kumar S: MEGA4: Molecular evolutionary genetics analysis (MEGA) software version 4.0. Mol Biol Evol 2007, 24:1596-1599.

12. Martin D, Rybicki E: RDP: detection of recombination amongst aligned sequences. Bioinformatics 2000, 16:562-563.

13. Padidam M, Sawyer S, Fauquet CM: Possible emergence of new geminiviruses by frequent recombination. Virology 1999, 265:218-225.

14. Martin DP, Posada D, Crandall KA, Williamson C: A modified bootscan algorithm for automated identification of recombinant sequences and recombination breakpoints. AIDS Res Hum Retrovir 2005, 21:98-102.

15. Smith JM: Analyzing the mosaic structure of genes. J Mol Evol 1992, 34:126-9.

16. Posada D, Crandall KA: Evaluation of methods for detecting recombination from DNA sequences: computer simulations. Proc Nat/ Acad Sci USA 2001, 98:13757-13762.

17. Gibbs MJ, Armstrong JS, Gibbs AJ: Sister-scanning: a Monte Carlo procedure for assessing signals in recombinant sequences. Bioinformatics 2000, 16:573-582.

18. Martin DP, Williamson C, Posada D: RDP2: recombination detection and analysis from sequence alignments. Bioinformatics 2005, 21:260-262.

19. Shan TL, Cui L, Dai XQ, Guo W, Shang XG, Yu Y, Zhang W, Kang YJ, Shen Q, Yang ZB, Zhu JG, Hua XG: Sequence analysis of an isolate of minute virus of canines in China reveals the closed association with bocavirus. $\mathrm{Mol}$ Biol Rep 2010, 37:2817-2820.

20. Ohshima T, Kishi M, Mochizuki M: Sequence analysis of an Asian isolate of minute virus of canines (canine parvovirus type 1). Virus Genes 2004, 29:291-296.

21. Malim MH, Emerman M: HIV-1 sequence variation: drift, shift, and attenuation. Cell 2001, 104:469-474. 
22. Simmonds P: Recombination and selection in the evolution of picornaviruses and other Mammalian positive-stranded RNA viruses. J Virol 2006, 80:11124-1140.

23. Liu W, Zhai J, Liu J, Xie Y: Identification of recombination between subgenotypes IA and IB of hepatitis A virus. Virus Genes 2010, 40:222-224.

24. Duffy S, Shackelton LA, Holmes EC: Rates of evolutionary change in viruses: patterns and determinants. Nat Rev Genet 2008, 9:267-276.

25. Kesebir D, Vazquez M, Weibel C, Shapiro ED, Ferguson D, Landry ML, Kahn JS: Human bocavirus infection in young children in the United States: molecular epidemiological profile and clinical characteristics of a newly emerging respiratory virus. J Infect Dis. 2006, 194:1276-1282.

doi:10.1186/1743-422X-8-182

Cite this article as: Fu et al: Recombination analysis based on the complete genome of bocavirus. Virology Journal 2011 8:182.

Submit your next manuscript to BioMed Central and take full advantage of:

- Convenient online submission

- Thorough peer review

- No space constraints or color figure charges

- Immediate publication on acceptance

- Inclusion in PubMed, CAS, Scopus and Google Scholar

- Research which is freely available for redistribution

Submit your manuscript at www.biomedcentral.com/submit 